\title{
EFEKTIFITAS BAHAN AJAR DAN MEDIA BERBASIS ICT PADA MATERI PERSAMAAN DAN FUNGSI KUADRAT
}

\author{
Swaditya Rizki ${ }^{1}$, Yunita Wildaniati ${ }^{2}$ \\ 1) 2) FKIP Universitas Muhammadiyah Metro \\ E-mail: swaditya.rizki@gmail.com ${ }^{1)}$ yunitawildaniati@yahoo.co.id ${ }^{2)}$
}

\begin{abstract}
The objectives of this research are to know the practicality and the effectiveness of the development of teaching material and ICT-based media toward learning outcome on material of quadratic equations and function. Research subjects are mathematics education students of FKIP Muhammadiyah University of Metro. Experimental design uses a before-after or one group pretest-posttest technique. The technique of collecting data uses the questionnaires and tests. Data analysis uses paired sample t-test. The results obtained by the value of sig. $=0.000$ where the value of $\alpha=0.05$ and the value of $t=6807>t_{\text {table }}=2,015$, so it can be concluded that the value of the pre-test and post-test was very significantly different. The marginal average was known that post-test value was greater than that of the pre-test, so it can be concluded that there was a significant effect of teaching materials and ICT-based media toward learning outcomes. In other words, the teaching materials and ICT-based media are very effective for teaching and learning.
\end{abstract}

Keywords: teaching material and media, ICT, quadratic equations and function.

\section{PENDAHULUAN}

Pembelajaran matematika dianggap sebagian peserta didik merupakan pelajaran yang sulit. Hal ini disebabkan masih rendahnya tingkat belajar peserta didik untuk mempelajari matematika, bisa dikarenakan materinya yang dianggap sulit atau bahkan dari bahan ajarnya yang membuat sulit peserta didik. Berbagai cara sudah banyak dikembangkan oleh para peneliti untuk mengatasi masalah tersebut, mulai dari mengubah metode pembelajaran tradisional menjadi pembelajaran kooperatif maupun mengembangkan perangkat pembelajarannya. Dari hasil pengamatan pada proses pembelajaran aljabar yaitu pada materi persamaan dan fungsi kuadrat, kebanyakan mahasiswa sulit untuk memahami konsep dasar dari materi tersebut. Dari contoh yang diberikan, mahasiswa 
masih bingung antara teori dasar atau rumus yang ada dengan contoh aplikasi dalam kehidupan sehari-hari (Rizki, 2015).

Perkembangan ICT yang begitu pesat membuat semua orang harus bergerak menyesuaikan dan memanfaatkannya dengan baik. Atas dasar permasalahan ini yang menjadi dasar melakukan penelitian untuk mengetahui efektifitas dari bahan ajar dan media berbasis ICT (Information and Communication Technology) yang telah dikembangkan. Dengan harapan bahwa bahan ajar dan media yang baik serta berbasis ICT serta peran guru/dosen dalam proses pembelajaran menyebabkan mahasiswa menjadi senang dan lebih mudah dalam memahami materi. Hal ini seperti yang dinyatakan oleh beberapa peneliti yang fokus dibidang pembelajaran berbasis ICT bahwa pembelajaran dengan komputer dan guru akan lebih efektif daripada pembelajaran dengan komputer saja atau guru saja.

Ada beberapa pendapat tentang definisi bahan ajar, diantaranya yaitu menurut Mudlofir (2011:128) "Bahan ajar yaitu segala bentuk bahan yang digunakan untuk membantu dalam proses pembelajaran. Bahan tersebut disusun dengan runtut dan sistematis baik tertulis maupun tidak tertulis. Sejalan menurut pendapat Amri dan Ahmadi (2010:159) "bahan ajar adalah segala bentuk bahan yang digunakan untuk membantu guru/instruktur dalam melaksanakan kegiatan belajar mengajar di kelas.

Masih menurut Mudlofir (2011:130) ada beberapa prinsip dalam bahan ajar yang dikemukakan yaitu menimbulkan minat baca, ditulis dan dirancang untuk siswa, menjelaskan tujuan instruksional, disusun berdasarkan pola belajar yang fleksibel, struktur berdasarkan kebutuhan siswa dan kompetensi akhir yang akan dicapai, memberikan kesempatan pada siswa untuk berlatih, mengakomodasi kesulitan siswa, memberi rangkuman, gaya penulisan komunikatif dan semi formal, kepadatan berdasarkan kebutuhan siswa.

Pembelajaran akan menjadi lebih baik jika pembelajaran tersebut memanfaatkan teknologi informasi dan komunikasi atau information and communications technology (ICT). Seperti pendapat Korucu dan Gunduz (2011) yang mengatakan bahwa "dalam pencapaian akademik yang menerima pembelajaran berbantuan komputer akan lebih tinggi dibandingkan dengan metode tradisional". Sependapat dengan Birgin, dkk (2009) yang menyarankan bagi para guru khususnya guru matematika untuk menggunakan komputer dalam proses pembelajarannya dikarenakan sangat efektif dan memberikan pengaruh yang positif terhadap siswa dan guru. Hal ini 
tentu menarik para peneliti untuk terus mengembangkan pembelajaran yang berbasis ICT.

Senada dengan pendapat Aqda, Hamidi, dan Rahimi (2011) yang menyatakan bahwa "faktanya komputer dapat mempengaruhi perkembangan kreatifitas dan menciptakan lingkungan belajar yang interaktif'. Selain itu menurut Dost and Saglam (2012) yang menyatakan bahwa untuk menciptakan pembelajaran yang aktif maka proses pembelajaran harus disertai dengan teknologi, khususnya dengan komputer. Lebih lanjut dalam penelitiannya diungkapkan bahwa penggunaan komputer dalam pembelajaran CAI (computer Assisted Instruction) dapat meningkatkan kesiapan pendidik dalam mengajar. Mereka pun menyarankan bagi semua pendidik dalam mempersiapkan pembelajaran harus menggunakan teknologi karena dapat meningkatkan sikap yang positif. Dari beberapa pendapat di atas dapat disimpulkan bahwa pembelajaran akan sangat efektif dan memberi pengaruh yang positif jika dalam pembelajaran tersebut menggunakan perangkat pembelajaran berbasis ICT. Kualitas perangkat pembelajaran yang baik tentunya harus memenuhi kriteria seperti yang dikemukan oleh Nieveen (dalam Tati, Zulkardi dan Hartono, 2009) yaitu (1) kevalidan (validity), kepraktisan (practicality), dan (3) keefektifan (effectiveness). Dari penjelasan tersebut tentunya perangkat pembelajaran harus memenuhi salah satunya yaitu keefektifan. Oleh karena itu tujuan penelitian ini yaitu untuk mengetahui kepraktisan dan efektifitas bahan ajar dan media berbasis ICT yang telah dikembangkan pada materi persamaan dan fungsi kuadrat.

\section{METODE PENELITIAN}

Penelitian ini akan dilaksanakan di Program Studi Pendidikan Matematika Universitas Muhammadiyah Metro pada mahasiswa semester 5 Tahun Akademik 2015/2016 dengan jumlah mahasiswa sebanyak 45 orang. Desain eksperimen menggunakan teknik before-after atau one-group pretest-posttest design (Sugiyono, 2014: 111). Eksperimen dilakukan dengan 2 kali perlakuan dimana perlakuan pertama yaitu proses pembelajaran awal dilakukan tanpa menggunakan bahan ajar berbasis ICT, kemudian dilakukan tes untuk mendapatkan nilai awal (nilai pre-test). Selanjutnya perlakukan kedua dilakukan menggunakan bahan ajar berbasis ICT dan dilakukan tes untuk mendapatkan nilai akhir (posttest). Adapun desain eksperimennya digambarkan seperti gambar berikut. 


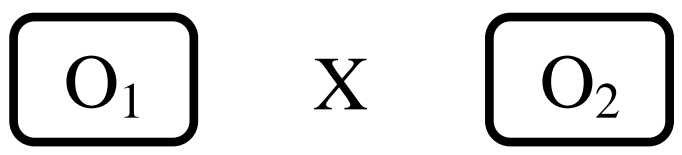

Gambar 1. Desain eksperimen (before-after).

Dimana $\mathrm{O}_{1}$ adalah sebelum perlakuan dan $\mathrm{O}_{2}$ adalah sesudah perlakuan, dan $\mathrm{X}$ adalah perlakuannya yaitu penggunaan bahan ajar dan media berbasis ICT.

Teknik pengumpulan data yang digunakan dalam penelitian ini pertama adalah angket yang digunakan untuk mengambil data kepraktisan bahan ajar dan media berbasis ICT, yang kedua menggunakan tes essay sebanyak 5 soal untuk soal pre-test dan posttest. Analisis data digunakan untuk mengetahui pengaruh/efektifitas sebelum dan sesudah perlakuan (before-after) yaitu menggunakan teknik analisis paired sample t-tes.

\section{HASIL PENELITIAN DAN PEMBAHASAN}

Hasil penelitian yang dicapai yaitu pada tahap ini dilakukan analisis kebutuhan yang berkaitan dengan pokok bahasan persamaan dan fungsi kuadrat untuk menggali masalah-masalah yang terjadi pada proses pembelajaran. Dari hasil angket yang sudah dianalisis yaitu sebagian mahasiswa masih belum pernah mengaplikasikan persamaan dan fungsi kuadrat ke dalam kehidupan sehari-hari. Disamping itu banyak mahasiswa yang sulit untuk menggambar grafik fungsi kuadrat. Selain itu juga mahasiswa belum pernah menemukan atau memakai media ICT yang seperti yang dikembangkan ini. Untuk bahan ajar pada materi persamaan kuadrat yang ada sekarang ini yaitu materi-materi yang dijelaskan tidak begitu lengkap, kebanyakan hanya sekilas saja. Selain itu contoh-contoh yang ada juga masih sangat dasar sehingga mahasiswa akan sangat sulit untuk memahami konsep materi tersebut. Untuk media sendiri sejauh ini belum ada program ICT yang mengembangkan materi persamaan kuadrat. Potensi dari penelitian dan pengembangan ini yaitu bahan ajar dan media yang dibuat yaitu berbasis ICT, sehingga mahasiswa yang mempelajari merasa tertarik untuk memahami materi. Disamping itu program pada media sangat membantu dalam memahami materi.

Produk yang digunakan yaitu bahan ajar persamaan dan fungsi kuadrat yang berbentuk buku teks yang dipadukan dengan ICT berupa powerpoint dan Excel. Powerpoint sendiri digunakan untuk menyajikan semua materi persamaan dan fungsi kuadrat 
yang ada, sedangkan Excel digunakan untuk menghitung ataupun mencari akar-akar persamaan kuadrat serta menggambar grafik fungsi kuadrat. Desain bahan ajar dan media berbasis ICT seperti yang dijelaskan dan ditampilkan oleh Rizki (2015:7).

Pada tahap ini yaitu ujicoba produk yang dilakukan pada kelas matematika FKIP Universitas Muhammadiyah Metro. Ujicoba kelas kecil dilakukan pada 1 kelas sebanyak 45 mahasiswa dengan 2 kali pertemuan. Dari hasil ujicoba tersebut diperoleh data tentang penilaian bahan ajar dan media berbasis ICT serta beberapa catatan dalam bahan ajar dan media tersebut. Dalam ujicoba tersebut proses pembelajaran dibagi menjadi 8 kelompok. Selain agar mahasiswa mudah dalam berdiskusi terhadap kepraktisan bahan ajar tersebut, ujicoba juga memerlukan laptop untuk ujicoba bahan ajar berbasis ICT tersebut. Dari hasil angket penilaian terhadap kepraktisan produk tersebut diperoleh data sebagai berikut.

Tabel 1. Rekapitulasi Hasil Ujicoba Kepraktisan Produk.

\begin{tabular}{|c|l|c|}
\hline No & \multicolumn{1}{|c|}{ Indikator Penilaian } & $\begin{array}{c}\text { Rata-rata } \\
\text { Penilaian } \\
(8 \text { kelompok })\end{array}$ \\
\hline 1 & $\begin{array}{l}\text { Jenis dan ukuran huruf, gambar, persamaan (equations) } \\
\text { sesuai dan cukup terlihat jelas. }\end{array}$ & 4,5 \\
\hline 2 & Tampilan bahan ajar secara keseluruhan menarik perhatian & 4,75 \\
\hline 3 & $\begin{array}{l}\text { Kesesuaian kalimat dengan taraf berpikir dan kemampuan } \\
\text { anda }\end{array}$ & 3,875 \\
\hline 4 & Kejelasan uraian materi pembelajaran pada bahan ajar & 3,75 \\
\hline 5 & $\begin{array}{l}\text { Kemanfaatan contoh-contoh yang diberikan (membantu anda } \\
\text { memahami materi) }\end{array}$ & 3,75 \\
\hline 6 & Kemudahan memahami materi dan contoh yang diberikan \\
\hline 7 & Kesesuaian antara bahan ajar dengan media pembelajaran. \\
\hline 8 & $\begin{array}{l}\text { Kesesuaian pemilihan warna dan penempatan tampilan, font, } \\
\text { tombol, dan background pada media (user friendly) }\end{array}$ & 4,75 \\
\hline 9 & Kesesuaian tombol-tombol menu dengan isi & 4,75 \\
\hline 10 & $\begin{array}{l}\text { Ketepatan perhitungan dalam media dengan perhitungan } \\
\text { manual }\end{array}$ & 4,875 \\
\hline 11 & $\begin{array}{l}\text { Ketepatan penggunaan grafik fungsi kuadrat dalam media } \\
\text { dengan grafik dalam teori }\end{array}$ & 4,75 \\
\hline 12 & Kesesuaian fungsi media dengan materi persamaan kuadrat & 4,75 \\
\hline 13 & Kesesuaian fungsi media dengan materi fungsi kuadrat & 4,75 \\
\hline 14 & $\begin{array}{l}\text { Manfaat media ICT terhadap pemahaman materi persamaan } \\
\text { dan fungsi kuadrat }\end{array}$ & 4,875 \\
\hline & \multicolumn{1}{|c|}{ Grand rata-rata } \\
\hline
\end{tabular}


Dari penilaian hasil ujicoba kepraktisan produk yang dilakukan pada 8 kelompok tersebut diperoleh grand rata-rata nilai sebesar 4,473 dari skala 5 atau sebesar $89,46 \%$. Dari nilai tersebut dapat disimpulkan bahwa kepraktisan bahan ajar berbasis ICT tersebut tergolong kriteria sangat baik. Sehingga bahan ajar berbasis ICT ini sangat baik untuk digunakan dalam proses pembelajaran.

Untuk mengetahui efektifitas dari bahan ajar berbasis ICT tersebut yaitu dilakukan eksperimen menggunakan desain before-after atau pretest-posttest dengan teknik analisis paired sample t-tes. Eksperimen dilakukan dengan 2 kali perlakuan dimana perlakuan pertama yaitu proses pembelajaran awal dilakukan tanpa menggunakan bahan ajar berbasis ICT, kemudian dilakukan tes untuk mendapatkan nilai awal (nilai pre-test). Selanjutnya perlakukan kedua dilakukan menggunakan bahan ajar berbasis ICT dan dilakukan tes untuk mendapatkan nilai akhir (post-test). Dari analisis data menggunakan SPSS diperoleh hasil sebagai berikut.

Tabel 2. Paired Samples Statistics

\begin{tabular}{|ll|r|r|r|r|}
\hline & \multicolumn{1}{|c|}{ Mean } & $\mathrm{N}$ & Std. Deviation & Std. Error Mean \\
\hline Pair 1 & Pre test & 61.62 & 45 & 15.633 & 2.330 \\
& Post test & 71.27 & 45 & 14.442 & 2.153 \\
\hline
\end{tabular}

Tabel 3. Paired Samples Correlations

\begin{tabular}{|l|r|r|r|}
\hline & $\mathrm{N}$ & Correlation & \multicolumn{1}{|c|}{ Sig. } \\
\hline Pair 1 Pre test \& Post test & 45 & .803 & .000 \\
\hline
\end{tabular}


ISSN 2442-5419 Vol. 4, No. 2 (2015) 1-8

Tabel 4. Paired Samples Test

\begin{tabular}{|c|c|c|c|c|c|c|c|c|}
\hline & \multicolumn{5}{|c|}{ Paired Differences } & \multirow[b]{3}{*}{$t$} & \multirow[b]{3}{*}{ df } & \multirow{3}{*}{$\begin{array}{l}\text { Sig. (2- } \\
\text { tailed) }\end{array}$} \\
\hline & \multirow[b]{2}{*}{ Mean } & \multirow{2}{*}{$\begin{array}{c}\text { Std. } \\
\text { Deviation }\end{array}$} & \multirow{2}{*}{$\begin{array}{l}\text { Std. } \\
\text { Error } \\
\text { Mean }\end{array}$} & \multicolumn{2}{|c|}{$\begin{array}{l}95 \% \text { Confidence } \\
\text { Interval of the } \\
\text { Difference }\end{array}$} & & & \\
\hline & & & & Lower & Upper & & & \\
\hline $\begin{array}{ll}\text { Pair } & \text { Pre test }- \\
1 & \text { Post test }\end{array}$ & 9.644 & 9.504 & 1.417 & -12.500 & -6.789 & 6.807 & 44 & .000 \\
\hline
\end{tabular}

Dari Tabel 2 dapat dilihat bahwa nilai rata-rata pre test dari 45 mahasiswa tersebut yaitu 61.62 dan rata-rata post test yaitu 71.27 dengan selisih rata-rata 9.65. Dari Tabel 3 diketahui nilai Sig. $=0.000$, dimana nilai $\alpha=0.05$, karena nilai Sig.< $\alpha$ sehingga dapat disimpulkan bahwa data nilai pretest dan post-test sangat berkorelasi, dimana nilai korelasinya sebesar 0.803 atau sebesar 80,3\%. Sedangkan dari Tabel 4 diketahui nilai Sig. = 0.000 dimana nilai $\alpha=0.05$, karena nilai Sig. $<\alpha$ atau nilai $\mathrm{t}_{\text {hitung }}=6.807$ $>\mathrm{t}_{\text {tabel }}=2.015$, sehingga dapat disimpulkan bahwa data nilai pretest dan post-test sangat berbeda signifikan. Jika dilihat dari rataan marginalnya diketahui bahwa nilai post-test lebih besar dari nilai pretest, sehingga dapat disimpulkan bahwa ada pengaruh yang sangat signifikan penggunaan bahan ajar berbasis ICT terhadap hasil belajar. Dengan kata lain, bahan ajar berbasis ICT tersebut sangat efektif untuk digunakan dalam proses pembelajaran.

\section{KESIMPULAN DAN SARAN}

Dari hasil penelitian ini dapat disimpulkan bahwa kepraktisan bahan ajar berbasis ICT tersebut tergolong kriteria sangat baik dengan nilai rata-rata sebesar 4,473 dari skala 5 atau sebesar $89,46 \%$. Sehingga bahan ajar berbasis ICT ini sangat baik untuk digunakan dalam proses pembelajaran. Lebih lanjut dari hasil analisis data dapat disimpulkan bahwa ada pengaruh yang sangat signifikan penggunaan bahan ajar berbasis ICT terhadap hasil belajar. Dengan kata lain, bahan ajar berbasis ICT tersebut sangat efektif untuk digunakan dalam pembelajaran pada materi persamaan dan fungsi kuadrat.

Saran untuk penelitian ini yaitu agar bahan ajar dan media berbasis ICT yang sudah ada dikembangkan menggunakan software lainnya, khususnya 
berbasis web. Selain itu dalam bahan ajar agar dapat dikembangkan lagi untuk tingkat SMP maupun SMA.

\section{DAFTAR PUSTAKA}

Amri, S. dan Ahmadi, I.K. 2010. Konstruksi Pengembangan Pembelajaran. Jakarta: Prestasi Pustaka

Aqda, M. F., Hamidi, F., dan Rahimi, M. 2011. The comparative effect of computer-aided instruction and traditional teaching on student's creativity in math classes. The Journal of Procedia Computer Science 3(2011), p.266-270.

Birgin, O., Cathoglu, H., Costu, S., and Aydin, S. 2009. The investigation of the views of student mathematics teachers towards computer-assisted mathematics instruction. The Journal of Procedia Social and Behavioral Sciences 46: Elsevier (2009), p.676-680

Dost, S. and Saglam, Y. 2012. Effect of preservice teachers' learning styles and field of study on computer-assisted instruction. The Journal of Procedia Social and Behavioral Sciences 46: Elsevier (2012), p.38123816
Korucu, A.T. dan Gunduz, S. 2011. The effects of computer assisted instruction practices in computer office program course on academic achievements and attitudes toward computer. The Journal of Procedia Social and Behavioral Sciences 15: Elsevier (2011), p.19311935.

Mudlofir, A. 2011. Aplikasi Pengembangan Kurikulum Tingkat Satuan Pendidikan dan Bahan Ajar. Jakarta: Raja Grafindo Persada

Rizki, S. 2015. Pengembangan Bahan Ajar Persamaan Dan Fungsi Kuadrat Berbasis ICT. Seminar Nasional Pendidikan MIPA. Universitas Lampung. ISBN: 978-979-3262-11-6.

Sugiyono. 2014. Metode Penelitian Pendidikan (Kuantitatif, Kualitatif, dan $R \& D)$. Bandung: Alfabeta.

Tati, Zulkardi, dan Hartono, Y. $2009 . \quad$ Pengembangan Perangkat Pembelajaran Berbasis Kontekstual Pokok Bahasan Turunan di Madrasar Aliyah Negeri 3 Palembang. Jurnal Pendidikan Matematika (2009), Volume 3. No.1. Universitas Sriwijaya, h.7589 